\title{
Compared decline of residual kidney function in patients treated with automated peritoneal dialysis and continuous ambulatory peritoneal dialysis: a multicenter study
}

\author{
Miguel Pérez Fontán ${ }^{\mathrm{a}}$, César Remón Rodríguez ${ }^{\mathrm{b}}$, Mercè Borràs Sans $^{\mathrm{c}}$, Emilio Sánchez \\ Álvarez ${ }^{\mathrm{d}}$, Marta da Cunha Naveira ${ }^{\mathrm{a}}$, Pedro Quirós Ganga ${ }^{\mathrm{b}}$, Beatriz López-Calviño ${ }^{\mathrm{e}}$, \\ Carmen Rodríguez Suárez ${ }^{\mathrm{d}}$, Ana Rodriguez-Carmona ${ }^{\mathrm{a}}$ \\ ${ }^{a}$ Division of Nephrology, a University Hospital A Coruña, A Coruña ${ }^{b}$ University Hospital Puerta Real, Cádiz, ${ }^{c}$ \\ University Hospital Arnau de Vilanova, Lleida, and d University Hospital of Asturias, Asturias , and ${ }^{e}$ Division of \\ Clinical Epidemiology, University Hospital A Coruña, A Coruña, Spain
}

\begin{abstract}
BACKGROUND: There is controversy concerning the compared rates of decline of residual kidney function (RKF) in patients treated with continuous ambulatory peritoneal dialysis (CAPD) and automated peritoneal dialysis (APD). OBJECTIVES AND METHOD: Following an observational, multicenter design, we studied 493 patients initiating peritoneal dialysis (PD) in four different Spanish units. We explored the effect of the PD modality on the rate of decline of RKF and the probability of anuria during follow-up. We applied logistic regression for intention-to-treat analyses, and linear mixed models to explore time-dependent variables, excluding those affected by indication bias. MAIN RESULTS: Patients started on APD were younger and less comorbid than those initiated on CAPD. Baseline RKF was similar in both groups $(\mathrm{p}=0.50)$. Eighty-seven patients changed their PD modality during follow-up. The following variables predicted a faster decline of RKF: higher (rate of decline) or lower (anuria) baseline RKF, younger age, proteinuria, nonprimary PD, use of PD solutions rich in glucose degradation products, higher blood pressure, and suffering peritonitis or cardiovascular events during follow-up. Overall, APD was not associated with a fast decline of RKF, but stratified analysis disclosed that patients with lower baseline RKF had an increased risk for this outcome when treated with this technique (HR: 2.26, 95\% CI: 1.09-4.82, $\mathrm{p}=0.023$ ). Moreover, the probability of anuria during follow-up was overtly higher in APD patients (HR: 3.22, 95\% CI: 1.25-6.69, $\mathrm{p}=0.002$ ).

CONCLUSIONS: Starting PD patients directly on APD is associated with a faster decline of RKF and a higher risk of developing anuria than doing so on CAPD. This detrimental effect is more marked in patients initiating PD with lower levels of RKF.
\end{abstract}

Keywords

Anuria; Automated peritoneal dialysis; Continuous; Ambulatory peritoneal dialysis; Kidney function; Proteinuria 


\section{Introduction}

Preservation of residual kidney function (RKF) offers multiple benefits to patients undergoing chronic peritoneal dialysis (PD), including easier management of uremic toxicity and hypervolemia, better control of several complications of chronic kidney disease, less stringent dietary restrictions and improved quality of life (QoL). Moreover, both RKF at the initiation of PD and its time course correlate with survival of these patients [1].

Many demographic and clinical factors have been claimed to influence the time course of RKF in PD patients [1]. Some of them (e.g. age) are not modifiable, but interventions on others may help to retard the natural decay of glomerular filtration rate (GFR). The latter comprise adequate control of blood pressure, reduction of proteinuria or avoidance of nephrotoxic drugs, among others. Some specific approaches have shown a beneficial effect for this purpose, including treatment with antagonists of the renin-angiotensin system (RAS) [2,3], use of PD solutions low in glucose degradation products (GDP) [4] or prevention of episodes of volume overload or dehydration $[5,6]$. Finally, the roles of other factors, including glucosesparing PD regimes, the use of icodextrinbased solutions or efficient prevention of peritoneal infections remain unproven or controversial.

The compared impact of continuous ambulatory PD (CAPD) and automated PD (APD) on the time course of RKF has been a recurrent matter of discussion since several studies, published in the late 1990s $[7,8]$, reported a faster decline of GFR in patients treated with the latter modality. Subsequently, several small randomized trials [9,10] and observational studies [11] have provided controversial results. This question is consequential because a potential handicap of APD in this field could influence the current policy of many centers of starting patients directly on APD, according to their personal preference or to general QoL perceptions.

We have undertaken a multicenter observational study to assess the role of a large group of demographic, clinical and dialysis-related variables on the time course of RKF (main outcome variable) in a population of incident patients on PD during a period of 11 years. Our primary focus was to disclose the compared impact of the modality of PD (study variable) on the main outcome variable.

\section{Method}

\section{General Design}

Following a multicenter, observational design, we analyzed the risk profile for decline of RKF in a cohort of patients starting PD therapy in four Spanish centers during a period of 11 years (2000- 2010). The participating centers had in common accepted standards of quality and a large experience with APD, which was indicated as a starting modality essentially for patient's preference and QoL reasons. Adequacy and ultrafiltration issues represented the most usual causes for later transfer from CAPD. APD was also recommended to facilitate management of some abdominal wall disorders in a small subset of patients, while fast small-solute peritoneal transport rates did not represent a sole indication for this technique in the participating centers.

The main objective of the study was to disclose the role of the modality of PD (APD vs. CAPD; main study variable) on the time course of RKF (main dependent variable). Additionally, we performed analyses aimed to assess the role of other controversial factors on the outcome of RKF.

The study complied with the requested ethical conditions for retrospective observational studies in the participating centers. 


\section{Study Population}

We analyzed all patients starting PD in four different Spanish centers between January 2000 and December 2010 who fulfilled the following inclusion criteria:

(1) Age older than 10 years

(2) Minimum follow-up of 6 months on PD

(3) Estimations of GFR at least at baseline and after 6 months on PD available

(4) Baseline 24-hour urine volume $\geq 300 \mathrm{ml} / 24 \mathrm{~h}$ and GFR $\geq 1 \mathrm{ml} / \mathrm{min}$

(5) Clinical records available

Table 1 displays the main baseline characteristics of patients, while table 2 depicts essential follow-up parameters. Data collection was closed on December 31, 2012.

Patients were treated with standard PD systems (Baxter, Deerfield, Illinois; Fresenius, Bad Homburg, Germany). Icodextrinbased solutions were fully available in all centers during the recruitment and followup periods. All centers followed accepted criteria for PD prescription. Dry-day APD was prescribed sporadically, and was not a subject of specific analysis.

Table 1. Baseline demographic and clinical characteristics of participants

\begin{tabular}{|c|c|c|c|c|}
\hline & All & CAPD & APD & $\mathrm{p}$ \\
\hline $\mathrm{n}$ & 493 & 368 & 125 & \\
\hline Gender (males/females) & $63.7 / 36.3$ & $64.0 / 36.0$ & $62.9 / 37.1$ & 0.83 \\
\hline Kidney disease & & & & 0.20 \\
\hline Glomerular & $74(15.0)$ & $48(13.0)$ & $26(21.0)$ & \\
\hline $31(6.3)$ & $21(5.7)$ & $10(8.1)$ & Systemic & $6(1.2)$ \\
\hline $3(0.8)$ & $3(2.4)$ & Diabetic nephropathy & $144(29.2)$ & $113(30.6)$ \\
\hline $31(25.0)$ & Other/unknown & $135(27.4)^{2}$ & $104(28.2)$ & $31(25.0)$ \\
\hline Diabetes mellitus & $189(38.3)$ & $145(39.3)$ & $44(35.5)$ & 0.52 \\
\hline Body weight, kg & $72.0 \pm 14.6$ & $72.1 \pm 14.0$ & $71.6 \pm 16.1$ & 0.71 \\
\hline BMI, $\mathrm{kg} / \mathrm{m}^{2}$ & $26.8 \pm 4.8$ & $27.0 \pm 4.8$ & $26.1 \pm 4.8$ & 0.10 \\
\hline Charlson's score & $4.3 \pm 2.2$ & $4.5 \pm 2.33$ & $8 \pm 1.8$ & $<0.001$ \\
\hline Systolic blood pressure, $\mathrm{mm} \mathrm{Hg}$ & $136 \pm 20$ & $136 \pm 19$ & $135 \pm 18$ & 0.53 \\
\hline Diastolic blood pressure, $\mathrm{mm} \mathrm{Hg}$ & $77 \pm 12$ & $76 \pm 11$ & $80 \pm 12$ & $<0.001$ \\
\hline Mean blood pressure, $\mathrm{mm} \mathrm{Hg}$ & $99 \pm 12$ & $96 \pm 12$ & $99 \pm 12$ & 0.046 \\
\hline Hemoglobin, g/dl & $11.3 \pm 1.6$ & $11.3 \pm 1.5$ & $11.3 \pm 1.7$ & 0.88 \\
\hline Albumin, $g / 1$ & $36.5 \pm 5.3$ & $36.5 \pm 5.3$ & $36.7 \pm 5.4$ & 0.66 \\
\hline Cholesterol, mg/dl & $174.4 \pm 50.3$ & $169.8 \pm 43.6$ & $188.2 \pm 64.7$ & 0.002 \\
\hline C-reactive protein, $\mathrm{mg} / \mathrm{dl}$ & $0.50(0.0 / 17.8)$ & $0.59(0.0 / 17.8)$ & $0.40(0.01 / 6.40)$ & 0.002 \\
\hline $\mathrm{GFR}, \mathrm{ml} / \mathrm{min}$ & $7.5 \pm 3.3$ & $7.5 \pm 3.4$ & $7.4 \pm 3.2$ & 0.50 \\
\hline Diuresis, $\mathrm{ml} / 24 \mathrm{~h}$ & $1,437 \pm 665$ & $1,418 \pm 654$ & $1,495 \pm 696$ & 0.26 \\
\hline Proteinuria, $\mathrm{mg} / 24 \mathrm{~h}$ & $1,733 \pm 2,379$ & $1,695 \pm 2,557$ & $1,947 \pm 1,795$ & 0.54 \\
\hline
\end{tabular}

Values represent means \pm SD or $\mathrm{n}(\%)$, except C-reactive protein (median with range). Comparisons by Student's $\mathrm{t}$ test, MannWhitney and $\chi^{2}$ distribution. $\mathrm{D} / \mathrm{P}=$ Dialysate-to-plasma ratio; $\mathrm{PET}=$ peritoneal equilibration test. 
Table 2. Prescription and clinical variables during follow-up

\begin{tabular}{|c|c|c|c|c|}
\hline & $\begin{array}{l}\text { Baseline } \\
(n=493)\end{array}$ & $\begin{array}{l}6 \text { months } \\
(\mathrm{n}=493)\end{array}$ & $\begin{array}{l}12 \text { months } \\
(\mathrm{n}=419)\end{array}$ & $\begin{array}{c}24 \text { months } \\
(\mathrm{n}=287)\end{array}$ \\
\hline Number of exchanges (24 h) & $3.5 \pm 3.0$ & $3.7 \pm 3.0$ & $3.8 \pm 4.0$ & $4.1 \pm 4.0$ \\
\hline Total volume infused, $1 / 24 \mathrm{~h}$ & $6.9 \pm 2.1$ & $7.4 \pm 2.4$ & $7.8 \pm 2.7$ & $8.5 \pm 3.0$ \\
\hline Peritoneal glucose load, g/24 h & $90 \pm 39$ & $97 \pm 48$ & $102 \pm 53$ & $114 \pm 61$ \\
\hline Number of antihypertensives & $1.7 \pm 1.1$ & $1.7 \pm 1.2$ & $1.7 \pm 1.2$ & $1.6 \pm 1.2$ \\
\hline RAS antagonists & $222(45.3)$ & $212(44.9)$ & $189(46.0)$ & $125(44.0)$ \\
\hline Dose of furosemide, $\mathrm{mg} / 24 \mathrm{~h}$ & $37.1 \pm 44.6$ & $62.7 \pm 60.8$ & $72.0 \pm 66.6$ & $70.4 \pm 68.9$ \\
\hline Systolic blood pressure, $\mathrm{mm} \mathrm{Hg}$ & $136 \pm 19$ & $134 \pm 19$ & $133 \pm 18$ & $132 \pm 18$ \\
\hline Diastolic blood pressure, $\mathrm{mm} \mathrm{Hg}$ & $77 \pm 12$ & $76 \pm 11$ & $75 \pm 11$ & $74 \pm 10$ \\
\hline
\end{tabular}

Figures denote means \pm SD and $\mathrm{n}(\%)$ (categorical). Values in bold represent significant difference vs. baseline. $\mathrm{D} / \mathrm{P}=\mathrm{Dialysate}-$ toplasma ratio; $\mathrm{PET}=$ peritoneal equilibration test.

\section{Study Variables}

RKF was estimated from the mean of urea and creatinine clearances in 24-hour urine collections (GFR) at baseline, and then after 6,12 and 24 months of follow-up. The main study variable was the modality of PD at the start of the second month of dialysis. This approach was undertaken because in some of the participating centers, APD patients are kept on CAPD for some weeks to permit familiarization with the latter technique. No patient was switched from CAPD to APD during the first month due to inadequacy of PD or decline of RKF. We also explored the role of selected variables on the time course of GFR, including blood pressure levels (clinical records), antihypertensive drugs and diuretics, use of RAS antagonists, proteinuria, use of PD solutions based on icodextrin or low in GDP, and the influence of cardiovascular (CV) events (demanding hospital admission) and peritoneal infections during the follow-up period for GFR (secondary study variables).

Control variables included common demographic, clinical, biochemical and prescription variables (tables 1,2). Hemoglobin, albumin, cholesterol, urea and creatinine levels were estimated with the help of autoanalyzers. C-reactive protein levels were estimated by immunoturbidimetry, and 24-hour proteinuria was estimated according to colorimetric methods.

\section{Strategy of Analysis and Statistics}

Numerical variables are presented as means \pm SD, unless there was markedly abnormal distribution (median with range). Categorical variables are presented as $\mathrm{n}(\%)$. Univariate comparisons were produced according to Student's t test, ANOVA, Mann-Whitney (numerical) and $\chi^{2}$ distribution (categorical) analyses.

During a preliminary analysis, we disclosed that age was the only variable showing an independent association with PD modality selection (probability of APD selection: 0.94 per year, $95 \%$ CI: $0.93-0.96$, $\mathrm{p}<0.0005)$. For this reason, age was a control variable in all multivariate analyses comparing CAPD and APD. 
The distribution of GFR was not normal, and linear regression models could not be applied due to a markedly abnormal distribution of residuals (Kolmogorov-Smirnov). This anomaly could not be corrected by logarithmic or other usual transformations. Consequently, we applied logistic regression for multivariate analyses concerning baseline variables (intention-to-treat approach), using as dependent variables a rate of decline of GFR above or below median values, and the probability of complete loss of GFR (anuria, defined by 24-hour urine volume diuresis $<100 \mathrm{ml} / 24 \mathrm{~h}$ or $\mathrm{GFR} \leq 0.2 \mathrm{ml} / \mathrm{min}$ ) during follow-up. CV events and peritoneal infections during the follow-up period were managed as binary, nontime-dependent factors during this phase. Median values of GFR decay were estimated for the period of follow-up of each subgroup of individuals because the decline of RKF was not linear (faster during the first year). We performed a general survey of interactions and stratified analyses, focusing on the baseline modality of PD.

Longitudinal analysis (as-treated approach) was carried out using linear mixed models with forward stepwise variable selection to estimate the effect of time-dependent variables on the evolution of GFR. Patient effect was adjusted as a random effect, while the covariates were adjusted as fixed effects. Associations between the variables studied and GFR were evaluated using beta coefficients, with 95\% CI, in the fixed-effects part of the models. All the secondary study variables were scrutinized under this strategy. Time-dependent associations between the modality of PD and other conditions of prescription on one side, and the time course of GFR on the other, were explored, but not considered for final analyses due to the likelihood of bias by indication (switch to APD and increasing prescription conditions more likely in patients with a faster decline of GFR). This presumed bias was confirmed by analysis of the compared characteristics of patients started on CAPD, according to later change to APD. Patients changing to APD displayed a similar baseline RKF ( $7.3 \pm 3.8$ vs. $7.6 \pm 3.4 \mathrm{ml} / \mathrm{min}, \mathrm{p}=0.51)$, but suffered a faster decline during the first 6 months of follow-up $(0.18 \pm 0.39 \mathrm{vs} .0 .05 \pm 0.50 \mathrm{ml} / \mathrm{min} / \mathrm{month}, \mathrm{p}=$ $0.027)$ and presented lower levels of GFR at the end of this period $(6.2 \pm 3.0 \mathrm{vs} .7 .4 \pm 3.8 \mathrm{ml} / \mathrm{min}, \mathrm{p}=$ 0.013) than patients who continued on CAPD.

We used SPSS 19.0 and Stata v.10 software for data management.

\section{Results}

\section{Overview}

Four hundred and ninety-three patients were studied, and 287 completed the scheduled maximal follow-up period of 24 months (tables 1, 2). Patients treated in different hospitals shared similar rates of decline of GFR ( $p=0.56$, ANOVA), although patients from one center (UHPR) initiated PD with a moderately lower GFR than the other three $(6.8 \pm 3.6 \mathrm{ml} / \mathrm{min}, \mathrm{p}=0.026)$.

Most variations from baseline were related to the natural decay of GFR and changes in the conditions of prescription of PD (table 2). Eighty-seven patients changed their PD modality during follow-up, with 81 of them switching from CAPD to APD (66 during the first year, and 15 during the second year). Patients treated with CAPD and APD made a similar use of icodextrin at inception (57.2 vs. 62.6\%, respectively, $\mathrm{p}=0.29)$, but there was a consistent trend to a higher use of this type of solution in APD patients, which was observable after the sixth month $(61.0$ vs. $74.5 \%, \mathrm{p}=0.003)$. However, low GDP solutions were used more frequently in CAPD patients after baseline (41.5 vs. $28.2 \%, \mathrm{p}=0.008)$. Similar proportions of CAPD and APD patients were treated with RAS antagonists at baseline and during followup.

Eighty-seven patients (18.0\%) experienced at least one CV event during follow-up, occurring $12.0 \pm$ 6.6 months after inception of PD. The main CV events included heart failure (26.2\%), peripheral revascularization or amputation $(23.6 \%)$, coronary events $(21.0 \%)$, and stroke $(10.0 \%)$. On the other hand, 188 patients $(38.5 \%)$ experienced at least one episode of peritonitis, starting $7.8 \pm 5.8$ months after initiation of PD. 


\section{Univariate Analysis}

Univariate analyses disclosed an association between a faster rate of decline of GFR and the following variables: kidney disease other than interstitial nephropathy $(\mathrm{p}=0.022)$, diabetes mellitus $(\mathrm{p}=0.046)$, origin other than primary incidence on PD $(p=0.023)$, higher systolic $(p=0.056)$ and diastolic $(p=0.01)$ blood pressure levels, number of antihypertensive drugs prescribed $(\mathrm{p}=0.02)$, higher C-reactive protein levels $(\mathrm{p}=0.035)$, higher GFR $(\mathrm{p}<0.0005)$ and 24-hour urine volume diuresis $(\mathrm{p}=0.003)$ at the start of $\mathrm{PD}$, and heavier proteinuria $(\mathrm{p}=0.003$; other variables not significant). The crude rates of decline of GFR were similar in patients started on CAPD $(0.13 \pm 0.25 \mathrm{ml} / \mathrm{min} / \mathrm{month})$ and APD $(0.15 \pm 0.20, \mathrm{p}=0.41)$. Univariate correlates of the development of anuria during follow-up are presented in table 3 . Figure $1 \mathrm{a}, \mathrm{b}$ depicts the time course of GFR and diuresis, respectively, according to the baseline modality of PD.

Table 3. Probability of anuria during follow-up according to baseline variables

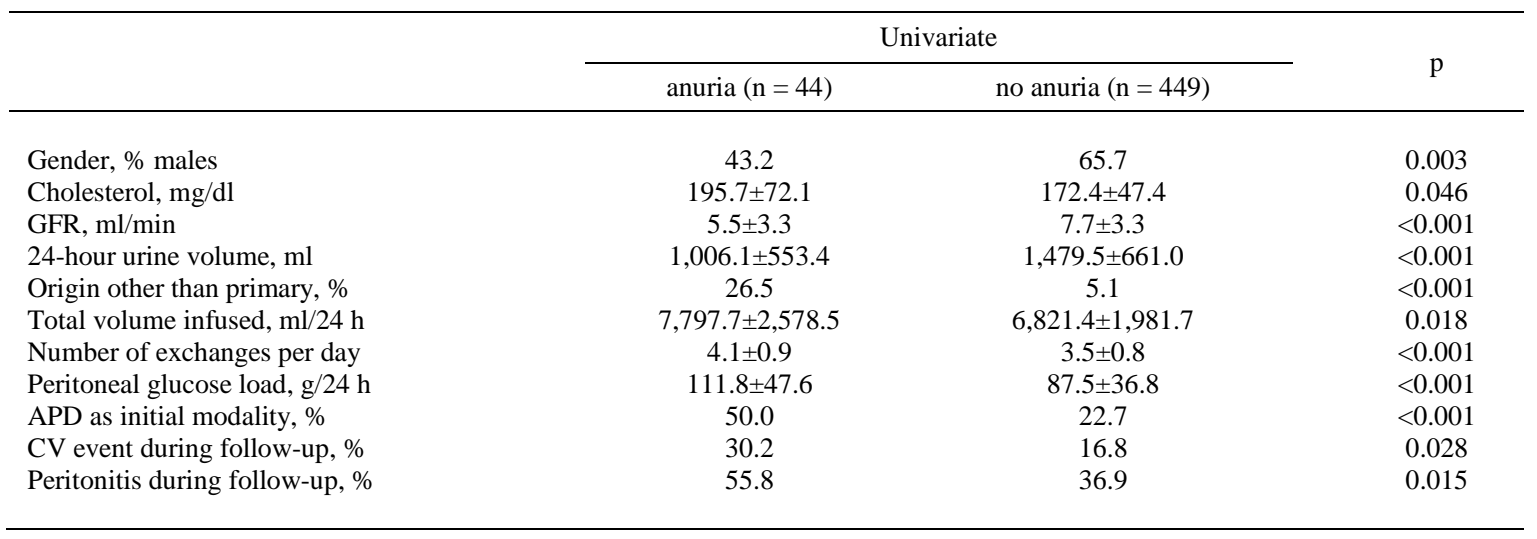

Only variables presenting significant differences.

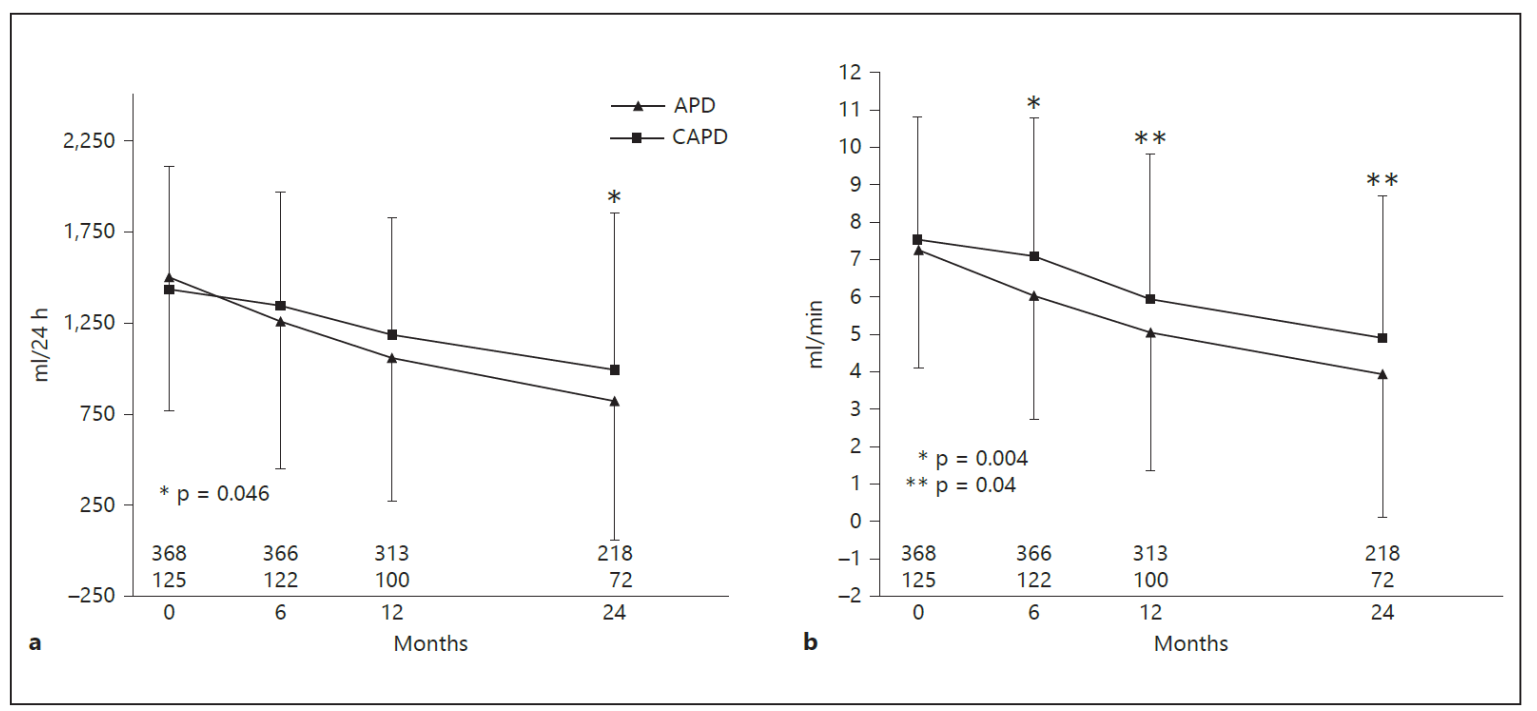

Fig. 1. a Time course of RKF (mean renal clearance) according to baseline modality of PD. b Evolution of 24-hour urine volume according to baseline modality of PD. Values denote means with SD. 
Table 4 depicts the variables showing an independent association (or trend) with a faster-than-median rate of decline of GFR. Higher baseline GFR, younger age and proteinuria were most consistently associated with a fast decline of GFR. PD after hemodialysis or transplant failure, poor control of blood pressure, and use of icodextrin for the long dwell were also associated with a relatively fast decay of GFR. Secondary analyses disclosed first-degree interaction terms between baseline GFR on one side and mean blood pressure $(\mathrm{p}=0.001)$ or the modality of PD $(\mathrm{p}=0.008)$ on the other.

Table 4. Decline of GFR during follow-up

\begin{tabular}{|c|c|c|c|}
\hline & \multicolumn{2}{|c|}{ Multivariate } & $\mathrm{p}$ \\
\hline Age ( $\times$ year $)$ & 0.98 & $0.97-0.99$ & 0.005 \\
\hline Origin other than incident & 2.68 & $1.29-6.13$ & 0.019 \\
\hline Baseline proteinuria $(\times \mathrm{g} / 24 \mathrm{~h})$ & 1.25 & $1.10-1.43$ & 0.001 \\
\hline CV event during follow-up & 2.27 & $1.29-4.02$ & 0.005 \\
\hline Baseline icodextrin & 0.67 & $0.44-1.02$ & 0.062 \\
\hline \multicolumn{4}{|l|}{ APD starting modality } \\
\hline All & 1.06 & $0.65-1.71$ & 0.83 \\
\hline Baseline GFR $>7.5 \mathrm{ml} / \mathrm{min}$ & 0.64 & $0.34-1.20$ & 0.16 \\
\hline
\end{tabular}

Logistic regression analysis. Dependent variable: decline of GFR above median value (corrected for follow-up).

Remarkably, the modality of PD did not appear to bear any overall influence on the time course of GFR. However, interaction term-oriented stratified analysis confirmed that for patients starting PD with a below-median GFR, APD was associated with a significantly faster decline of GFR, which was not observed for patients starting with above-median GFR levels (table 4).

\section{Multivariate Analysis Relating Baseline Variables with the Probability of Anuria during Follow-Up}

Table 5 displays the variables independently associated with a higher risk of complete loss of RKF during follow-up. Again, baseline GFR was a strong predictor of this outcome, but in this case the correlation was inverse, indicating that starting PD with a lower level of GFR increased the probability of anuria. Nonprimary PD and the development of a CV event during follow up also portended a higher risk of anuria. Finally, APD was associated with a significant risk of anuria in the whole sample. Similarly to the previous case, the compared risk with CAPD was higher in patients initiating PD with lower levels of GFR, although in this case the difference between both groups was less marked, and the corresponding interaction term did not reach statistical significance. 
Table 5. Probability of anuria during follow-up according to baseline variables

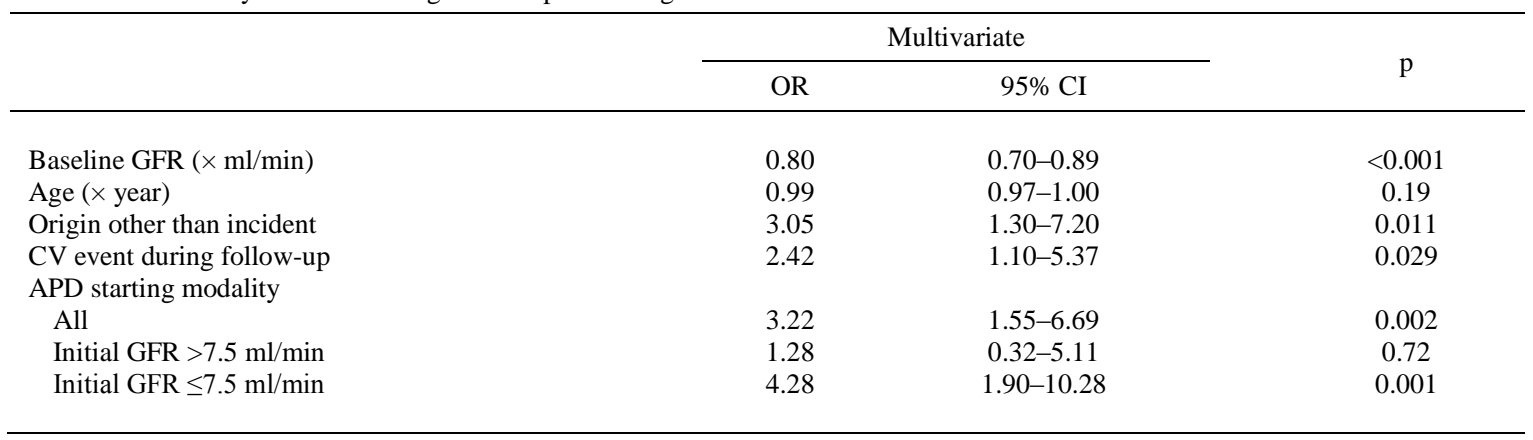

\section{Time-Dependent, Multivariate Analysis of GFR}

Mixed models confirmed the expected associations between the natural decay of GFR on one side, and the conditions of prescription (total dialysate volume and number of exchanges per $24 \mathrm{~h}$, peritoneal glucose load, daily ultrafiltration), including the modality of PD (B $=-0.857,95 \%$ CI: $-1.265 /-0.449$, $\mathrm{p}<$ 0.001 ), on the other (other data not presented). Table 6 shows the results focused on time-dependent variables with a lower risk of bias by indication for the time course of GFR. Both peritoneal infection and $\mathrm{CV}$ events during follow-up showed a consistent association with the rate of decline of GFR. In addition, the use of low-GDP solutions showed an apparent protective effect on GFR in this model. However, we could not demonstrate an association between the time course of RKF and other variables, including blood pressure levels or the use of RAS antagonists or icodextrin- based solutions.

Table 6. Mixed model analysis to assess the effect of time-dependent variables on the rhythm of decline of GFR

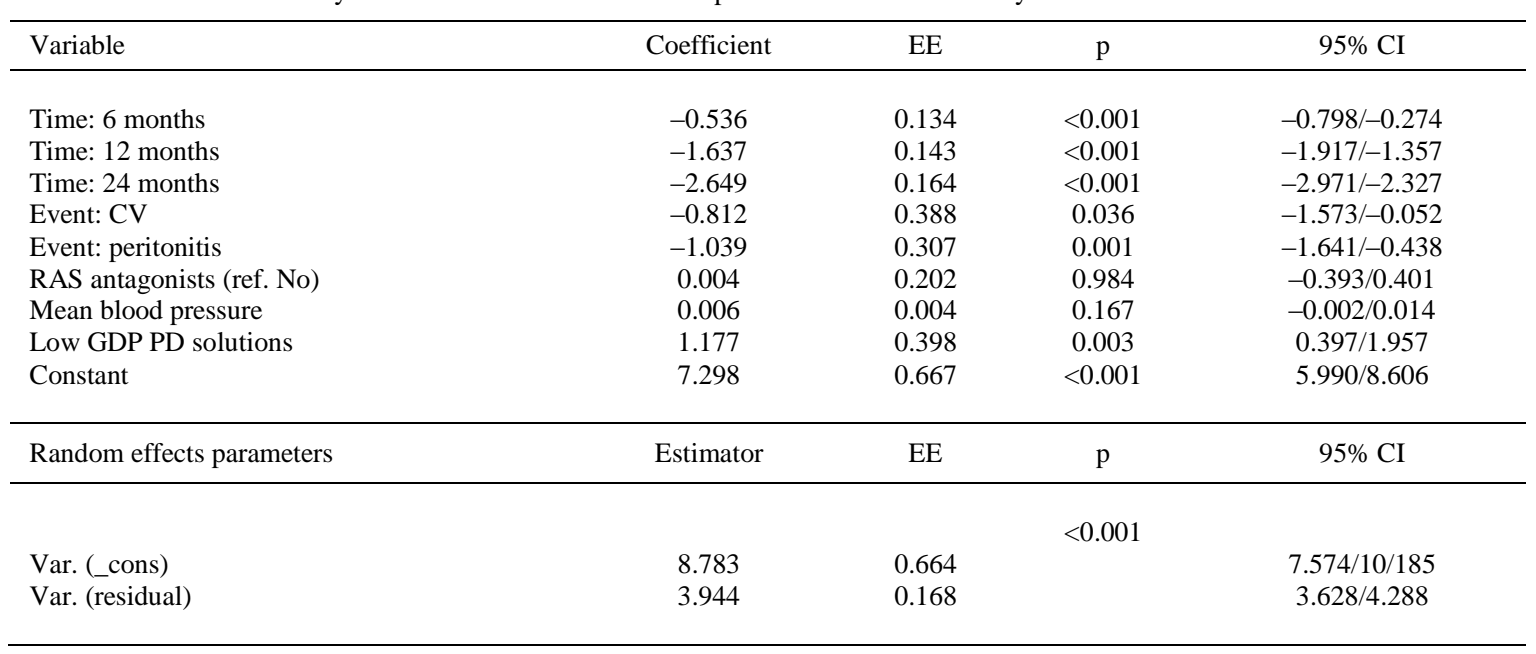

Dependent variable: GFR. Negative coefficients denote a detrimental effect, and positive coefficients denote a positive effect on the time course of GFR. AIC: 7,686.126; BIC: 7,766.613. 


\section{Discussion}

The results of the present study give support to the concern for a detrimental effect of APD on the time course of RKF. This question has been a recurrent matter of controversy [11] since first raised in the second half of the 1990s [7, 8], with some observational studies disclosing differences [12, 13] which other investigations have been unable to detect [14-17]. There are several potential explanations for these discrepancies. The first is the paucity and small size of randomized studies addressing this question [9, 10]. A majority of the cohort studies were also small, and clearly underpowered to detect differences. This problem has often been aggravated by imbalances between the compared groups (most patients on CAPD, few on APD). In addition, observational studies suffer a permanent risk of methodological biases. For instance, PD registries may show similar demographic characteristics for CAPD and APD patients at large $[13,18]$, but in practice the criteria for assignment of the modality of PD may not be equilibrated. For example, individual preference and QoL issues may encourage the use of APD in younger and healthier patients, who enjoy an active lifestyle. Conversely, APD is a common choice for older patients in countries which provide assisted PD [19].

RKF may also influence the selection of the modality of PD. Thus, in centers which emphasize indication for adequacy reasons, patients with lower levels and faster rates of decline of RKF may be overassigned to APD. On the other hand, many patients switch their initial PD modality during follow-up (most commonly CAPD to APD), further complicating data analyses. Time-dependent approaches could compensate for this problem but are difficult to apply, due to the risk of bias by indication, because transfer from CAPD to APD is often undertaken when RKF declines and more intensive prescriptions are needed. Overall, the possibility that patients prone to a rapid decline of RKF are treated with APD rather than with CAPD, either since inception or during follow-up, is always present in cohort studies, and must be addressed with particular care during statistical analyses.

There are other possible reasons for the above-mentioned discrepancies, including the variability of the strategies of prescription of APD. For instance, the choice of intensive versus incremental prescription policies, as well as the variable use of intermittent (dry-day) APD, may explain some differences among studies. Finally, the particularities of the dependent variable (rate of decline of RKF) may represent another issue. First, RKF has been estimated using different methods, which may not be equivalent. In addition, the decline of RKF is not linear, which complicates statistical analyses.

The reasons why RKF should decline faster during APD than during CAPD therapy are also controversial, but some claimed hemodynamic effects of the former technique could help to explain the difference. APD uses higher fill volumes than CAPD, and the conditions of prescription (frequent short cycles, more intensive ultrafiltration) during the night session are relatively aggressive. These two factors have been shown to result in hemodynamic disturbances, including significant oscillations in cardiac output and peripheral resistance [20,21]. These changes may accelerate the decay of RKF. On the other hand, more intensive APD schedules associate significant peritoneal glucose loads [22], which may impact negatively on RKF, either through generation of GDP [23] or indirectly by worsening metabolic disease. Remarkably, the peritoneal glucose load at the start of PD was not a consistent predictor of the decline of RKF in our study.

According to our results, patients started directly on APD underwent a faster decline of RKF than those treated with CAPD. This effect was overt when we explored the risk of anuria during follow-up (table 5). On the other hand, the rate of decline of RKF was not globally different between CAPD and APD patients (table 4), but APD was also clearly detrimental for RKF in the subset of patients started on PD with lower levels of GFR. The reasons for the latter finding are not totally clear, but we suggest that this subgroup of patients demanded more aggressive ultrafiltration and higher peritoneal glucose loads, a setting in which APD could be particularly harmful. A recent study [13] observed a time-dependent interaction between baseline GFR and the modality of PD. During the first year of follow-up, patients with a higher baseline GFR did significantly worse under APD than under CAPD therapy. However, during the second and third years, an opposite trend was observed although, in the latter case, the difference was not statistically significant. 
Our analysis confirms previous reports showing younger age, poor blood pressure control or heavier proteinuria at the start of PD is associated with a fast decline of RKF [1]. In addition, patients initiating PD after hemodialysis and, particularly, after failure of a kidney transplant also suffered a relatively rapid loss of RKF (tables 4, 5) [24, 25]. Icodextrin showed a marginal protective effect on the time course of RKF, but the association did not reach statistical significance (table 4). On the other hand, the results of time-dependent analysis (table 6) suggest that low-GDP solutions may protect RKF, in agreement with several previous reports [4]. Moreover, clinical events (peritonitis, CV events) during follow-up had a clear impact on the time course of RKF. Peritonitis has previously been reported to influence RKF negatively $[15,17]$. Regarding CV events, episodes of heart failure have been most commonly claimed to be harmful to RKF $[5,26]$. However, we did not detect any beneficial effect of treatment with RAS antagonists on RKF. At least two small randomized studies have detected such an effect [2, 3], but a recent observational study also has not observed this [13].

The main limitation of our study is its observational, nonrandomized design, which demands specific strategies to overcome potential biases. The study population was relatively large, but may still have been insufficient to categorize some effects. Among its strengths, clinical records were rather complete, permitting analysis of the most important variables. The multicentric strategy also improved the quality of the study. Importantly, the distribution of patients between the study groups was more balanced than in any previous study, allowing more stable and reliable estimations.

In summary, starting PD therapy by APD may be associated with a faster decline of RKF and a higher probability of developing anuria during follow-up than doing so with CAPD. This handicap is apparently restricted to patients who initiate treatment with relatively low levels of RKF. These findings should be taken into consideration at the time of selecting the modality of PD in patients starting this therapy. Other factors which correlate independently with a relatively rapid decay of RKF include younger age, marked proteinuria, poor control of blood pressure and origin other than primary incidence of PD. Timedependent analyses also indicate that the use of conventional rather than low-GDP solutions and suffering peritoneal infections or significant $\mathrm{CV}$ events during follow-up also portend a faster decline of RKF.

\section{References}

1. Perl J, Bargman JM: The importance of residual kidney function for patients on dialysis: a critical review. Am J Kidney Dis 2009; 56: 1068-1081.

2. Li PK, Chow KM, Wong TY, Leung CB, Szeto CC: Effects of angiotensin-converting enzyme inhibitor on residual renal function in patients receiving peritoneal dialysis. Ann Intern Med 2003; 139: 105-112.

3. Suzuki H, Kanno Y, Sugahara S, Okada H, Nakamoto H: Effect of an angiotensin II receptor blocker, valsartan, on residual renal function in patients on CAPD. Am J Kidney Dis 2004; 43: 1056-1064.

4. Cho Y, Johnson DW, Badve SV, Craig JC, Strippoli GF, Wiggins KJ: The impact of neutral pH peritoneal dialysates with reduced glucose degradation products on clinical outcomes in peritoneal dialysis patients. Kidney Int 2013; 84: 969-979.

5. Moist LM, Port FK, Orzol SM, Young EW, Ostbye T, Wolfe RA, Hulbert-Shearon T, Jones CA, Bloembergen WE: Predictors of loss of residual renal function among new dialysis patients. J Am Soc Nephrol 2000; 11: 556-564.

6. Jansen MA, Hart AA, Korevaar JC, Dekker FW, Boeschoten EW, Krediet RT: Predictors of decline of residual renal function in incident dialysis patients. Kidney Int 2002; 62: 1046-1053.

7. Hiroshige K, Yuu K, Soejima M, Takasugi M, Kuroiwa A: Rapid decline of residual renal function in patients on automated peritoneal dialysis. Perit Dial Int 1996; 16: 307-315.

8. Hufnagel G, Michel C, Queffelou G, Skhiri H, Damieri H, Mignon F: The influence of automated peritoneal dialysis on the decrease in residual renal function. Nephrol Dial Transplant 1999; 14: 12241228.

9. de Fijter CW, Oe LP, Nauta JJ, van der Meulen J, Verbrugh HA, Verhoef J, Donker AJ: Clinical efficacy and morbidity associated with continuous cyclic compared with continuous ambulatory peritoneal dialysis. Ann Intern Med 1994; 120: 264-271.

10. Bro S, Bjorner JB, Tofte-Jensen P, Klem S, Almtoft B, Danielsen H, Meincke M, Friedberg M, FeldtRasmussen B: A prospective, randomized multicenter study comparing CAPD and APD treatment. Perit Dial Int 1999; 19:526-533. 
11. Bieber SD, Burkart J, Golper TA, Teitelbaum I, Mehrotra R: Comparative outcomes between continuous ambulatory and automated peritoneal dialysis: a narrative review. Am J Kidney Dis 2014; 63: 1027-1037.

12. Rodríguez-Carmona A, Perez Fontan M, Garcia Naveiro R, Villaverde P, Peteiro J: Compared time profiles of ultrafiltration, sodium removal, and renal function in incident CAPD and automated peritoneal dialysis patients. Am J Kidney Dis 2004; 44: 132-145.

13. Michels WM, Verduijn M, Grootendorst DC, le Cessie S, Boeschoten EW, Dekker FW, Krediet RT: Decline in residual renal function in automated compared with continuous ambulatory peritoneal dialysis. Clin J Am Soc Nephrol 2011; 6: 537-542.

14. Holley JL, Aslam N, Bernardini J, Fried L, Piraino B: The influence of demographic factors and modality on loss of residual renal function in incident peritoneal dialysis patients. Perit Dial Int 2001; 21: 302-305.

15. Johnson DW, Mudge DW, Sturtevant JN, Hawley CM, Campbell SB, Isbel NM, Hollett P: Predictors of decline of residual renal function in new peritoneal dialysis patients. Perit Dial Int 2003; 23: 276283.

16. Cnossen TT, Usvyat L, Kotanko P, van der Sande FM, Kooman JP, Carter M, Leunissen KM, Levin NW: Comparison on outcomes on continuous ambulatory peritoneal dialysis versus automated peritoneal dialysis: results from a USA database. Perit Dial Int 2011; 31: 679-684.

17. Badve SV, Hawley CM, McDonald SP, Brown FG, Boudville C, Wiggins KJ, Bannister KM, Johnson DW: Use of aminoglycosides for peritoneal dialysis-associated peritonitis does not affect residual renal function. Nephrol Dial Transplant 2012; 27: 381-387.

18. Mehrotra R, Chiu YW, Kalantar-Zadeh K, Vonesh E: The outcomes of continuous ambulatory peritoneal dialysis and automated peritoneal dialysis are similar. Kidney Int 2009; 76: 97-107.

19. Lobbedez T, Verger C, Ryckelynck JP, Fabre E, Evans D: Is assisted peritoneal dialysis associated with technique survival when competing events are considered? Clin J Am Soc Nephrol 2012; 7: 612-618.

20. Selby NM, Fonseca S, Hulme L, Fluck RJ, Taal MW, McIntyre CW: Automated peritoneal dialysis has significant effects on systemic hemodynamics. Perit Dial Int 2006; 26: 328-335.

21. Ivarsen P, Povlsen JV, Jensen JD: Increasing fill volume reduces cardiac performance in peritoneal dialysis. Nephrol, Dial Transplant 2007; 22: 2999-3004.

22. Demetriou D, Habicht A, Schillinger M, Hörl WH, Vychytil A: Adequacy of automated peritoneal dialysis with and without manual daytime exchange: a randomized controlled trial. Kidney Int 2006; 70: 1649-1655.

23. Justo P, Sanz AB, Egido J, Ortiz A: 3,4-Dideoxyglucosone-3-ene induces apoptosis in renal tubular epithelial cells. Diabetes 2005; 54: 2424-2429.

24. Davies SJ: Peritoneal dialysis in the patient with a failing allograft. Perit Dial Int 2001; 21(suppl 3):S280-S284.

25. Madar H, Korzets A, Ori Y, Herman M, Levy-Drummer RS, Gafter U, Chagnac A: Residual renal function in peritoneal dialysis after renal transplant failure. Perit Dial Int 2010; 30: 470-474.

26. Singhal MK, Bhaskaran S, Vidgen E, Bargman JM, Vas SI, Oreopoulos DG: Rate of decline of residual renal function in patients on continuous ambulatory peritoneal dialysis and factors affecting it. Perit Dial Int 2000; 20: 429-438. 